CLINICAL STUDY

\title{
Cyclin E correlates with malignancy and adverse prognosis in adrenocortical tumors
}

Frédérique Tissier, Albert Louvel, Sophie Grabar ${ }^{1}$, Anne-Marie Hagnéré, Jérôme Bertherat ${ }^{2}$, Marie-Cécile Vacher-Lavenu, Bertrand Dousset ${ }^{3}$, Yves Chapuis ${ }^{3}$, Xavier Bertagna ${ }^{2}$ and Christine Gicquel ${ }^{4}$

Service d'Anatomie Pathologique, ${ }^{1}$ Biostatistique et Informatique Médicale, ${ }^{2}$ Service des Maladies Endocriniennes et Métaboliques, ${ }^{3}$ Chirurgie Viscérale, Hôpital Cochin, AP-HP, 75014 Paris, ${ }^{4}$ Laboratoire d'Explorations Fonctionnelles Endocriniennes, Hôpital Trousseau, AP-HP, 75012 Paris and Réseau Comete, France

(Correspondence should be addressed to F Tissier; Email: frederique.tissier@cch.ap-hop-paris.fr)

\begin{abstract}
Objective: In many cases, the prognosis of an adrenocortical tumor cannot be determined from pathologic findings alone. We investigated cyclin E levels as a potential marker.

Methods: We studied 57 tumors by immunohistochemical staining with an anticyclin E antibody. We also evaluated clinical and pathologic factors (McFarlane staging and Weiss score) and previously validated genetic markers (17p13 loss of heterozygosity, $11 \mathrm{p} 15$ uniparental disomy, and overexpression of the IGF-II gene) for these tumors. Disease-free survival was estimated in 49 patients who underwent curative surgery.

Results: Cyclin E overproduction ( $\geq 5 \%$ ) was associated with the malignant phenotype and was strongly correlated with tumor size $(P<0.0001)$, Weiss score $(P<0.0001)$ and the presence of genetic abnormalities in tumors $(P<0.001)$ (nonparametric Wilcoxon test and Fisher's exact test). Within a median follow-up of 44.1 months, seven patients exhibited a recurrence and two patients died from other causes. Cyclin E overproduction was significantly associated with shorter diseasefree survival in univariate analysis $(P=0.016$; RR: 7.6), as were histologic grade (Weiss score $\geq 4 ; P=0.0006$; RR: 18$), 17 \mathrm{p} 13 \mathrm{LOH}(P=0.014$, RR: 14.9), 11p15 UPD ( $P=0.003$, RR: 11.8) and overexpression of the IGF-II gene $(P=0.015$, RR: 13.8).

Conclusion: This study shows that cyclin E overproduction is of adverse prognostic significance in adrenocortical tumors.

European Journal of Endocrinology 150 809-817
\end{abstract}

\section{Introduction}

Adrenocortical carcinomas are tumors with a poor prognosis (1). In cases of localized adrenocortical tumors (McFarlane stages I and II) (2), pathologic examination with determination of Weiss score has been shown to be useful for distinguishing between benign and malignant tumors (3). However, the results of this examination are ambiguous in some cases (4). Recent studies of these tumors have shown that genetic markers are associated with malignant phenotype (4-14). These genetic abnormalities consist of strong overexpression of the IGF-II gene and maternal 11 p15 uniparental disomy (UPD) with loss of the maternal allele and duplication of the active IGF-II paternal allele $(6,7,9), 17 \mathrm{p} 13$ loss of heterozygosity $(\mathrm{LOH})(4,5,8), 2 \mathrm{p} 16 \mathrm{LOH}(10)$ and $11 \mathrm{q} 13 \mathrm{LOH}$ (10-13). In malignant tumors, we previously showed that maternal $11 \mathrm{p} 15 \mathrm{UPD}$ is responsible for the loss of expression of the CDKN1C (also known as p57KIP2) gene (15). This gene encodes a cyclin-dependent kinase inhibitor (CKI) involved in the G1/S phase of the cell cycle. We also showed that the production of G1 cyclins and G1 cyclin-dependent kinases (CDK), including cyclin $\mathrm{E}$ and $\mathrm{CDK} 2$, is upregulated in tumors overexpressing the IGF-II gene (15). Cyclins, particularly G1 cyclins, play an important role in the transformation and progression of many cancers (16, 17). Cyclin E production is increased in a number of human cancers including esophageal, gastrointestinal, liver, genitourinary, hematologic, lung, skin, breast and smooth tissue cancers (17-35). Cyclin E levels may also provide prognostic information, and cyclin $\mathrm{E}$ could even be a potential target for anticancer treatment (17). Cell-cycle components have not been extensively investigated in adrenocortical tumors and the prognostic value of cyclin $\mathrm{E}$ levels remains to be evaluated.

The aim of this study was to evaluate cyclin E levels by immunohistochemical means in a series 
of 57 well-documented sporadic adrenocortical tumors and to assess the prognostic value of this marker. We found that cyclin E overproduction was associated with malignancy and was a good predictor of shorter disease-free survival in adrenocortical tumors.

\section{Patients and methods}

\section{Patients}

Between 1987 and 1998, sporadic adrenocortical tumor (other than Conn's adenoma) was diagnosed in 57 adult patients attending the Endocrinology Department of Cochin Hospital (Paris, France). This group of 57 patients was from among the patients reported in a previous study (4). None of these patients presented features of any tumor-predisposing syndrome (Beckwith-Wiedemann, McCune-Albright, multiple endocrine neoplasia type 1 or $\mathrm{Li}$-Fraumeni syndromes). Clinical data and hormonal status were evaluated as previously described (1). Tumor stage was assessed according to the McFarlane classification (2). Informed consent for the analysis of leukocyte and tumor DNA and for access to the data collected was obtained from all the patients, and the study was approved by an institutional review board (Comité Consultatif de Protection des Personnes dans la Recherche Biomédicale, Cochin Hospital, Paris). After surgery, patients were examined twice a year for 2 years and annually thereafter. Hormonal evaluation, chest radiograph, and computerized tomography (CT) scans of the abdomen and thorax were carried out at each evaluation. The patients were followed until their date of death, their last examination or the end of the follow-up period. The minimal follow-up period was 12 months.

\section{Microscopy}

The tumors were fixed in formalin and embedded in paraffin, and $4 \mu \mathrm{m}$ sections were cut and stained with hematoxylin and eosin. The sections were examined (A.L.) to assess Weiss score (0-9) (3) on the basis of the presence or absence of the following nine histologic features: high mitotic rate, atypical mitoses, high nuclear grade, low percentage of clear cells, necrosis, diffuse tumor architecture, capsular invasion, sinusoidal invasion and venous invasion.

\section{Genetic analysis}

The allelic status at $17 \mathrm{p} 13$ and $11 \mathrm{p} 15$ loci and the evaluation of IGF-II messenger content in tumors were performed as previously described (9).

\section{Immunohistochemical staining}

Sections of $4 \mu \mathrm{m}$ from formalin-fixed tissue embedded in paraffin were mounted on Superfrost/Plus glass slides. The paraffin was eliminated by incubating the sections in xylene and then rehydrating them. For antigen retrieval, sections were heated in a microwave oven for a total of $20 \mathrm{~min}$ in $10 \mathrm{mmol}$ sodium citrate buffer at $\mathrm{pH}$ 6.0. The slides were incubated with monoclonal anticyclin E antibody (C-19, Santa Cruz Biotechnology, Santa Cruz, CA, USA) at a dilution of 1:200 for $60 \mathrm{~min}$ at room temperature. Sections were then incubated with the streptavidin-biotin-peroxidase complex, and the marker was detected by the enzymatic precipitation of 3.3'-diaminobenzidine tetrahydrochloride in $0.5 \mathrm{mmol}$ Tris. The slides were counterstained with Mayer's hematoxylin.

Immunostaining was assessed at a multihead microscope by two independent pathologists (F.T. and A.L.) blinded to McFarlane stage, Weiss score and outcome. For the few discrepant cases, a consensus was reached by a new joint examination of the slides. Cells with nuclear staining were scored as stained cells (36). The cyclin E-stained sections were all examined at high magnification, and a labeling index (LI; percentage of stained cells) was attributed to each case. The intensity of staining was not scored. Cyclin E staining was considered negative if the cyclin E LI was $<5 \%$ and positive if the cyclin E LI was $\geq 5 \%$. We chose to use $5 \%$ as the cutoff value on the basis of previous studies (36).

\section{Statistical analysis}

Disease-free survival was estimated in patients with curative surgery by the method of Kaplan-Meier. Disease-free survival was the time in months between the initial operation and documented recurrence or the end of the study. Survival was censored if the patient was still alive or had died from other causes. Survival curves were compared and tested for statistical significance by log rank tests (univariate analysis).

Cox proportional hazard model was used to study the independent prognostic value of cyclin E expression on disease-free survival, adjusted for $17 \mathrm{p} 13 \mathrm{LOH}$ and Weiss score in patients who had these data available (bivariate analysis).

The chi-square and Wilcoxon tests were used to compare groups for noncensored qualitative and quantitative variables respectively. The threshold for significance was $P \leq 0.05$. Calculations were performed with the SAS package (SAS Institute, Inc, Cary, NC, USA).

\section{Results}

\section{Features at presentation}

The characteristics of the patients are summarized in Table 1. The patients were 23-79 years old $(44.9 \pm 15.1$ years). The ratio of women to men was $51 / 6$. Forty-seven patients (82\%) were referred for endocrine symptoms, and 51 patients $(90 \%)$ presented 
Table 1 Features at presentation in 57 patients with sporadic adrenocortical tumors.

\begin{tabular}{|c|c|c|c|c|}
\hline & $\begin{array}{l}\text { All patients } \\
\quad(n=57)\end{array}$ & $\begin{array}{c}\text { McFarlane stage I } \\
(\leq 5 \mathrm{~cm}) \\
(\text { localized }) \\
(n=31)\end{array}$ & $\begin{array}{c}\text { McFarlane stage II } \\
(>5 \mathrm{~cm}) \\
(\text { localized }) \\
(n=14)\end{array}$ & $\begin{array}{c}\text { McFarlane stage III-IV } \\
\text { (disseminated) } \\
(n=12)\end{array}$ \\
\hline Age (mean \pm S.D.) & $44.9 \pm 15.1$ & $44.4 \pm 15.5$ & $45.2 \pm 13.4$ & $45.8 \pm 16.9$ \\
\hline Sex $(F / M)$ & $51 / 6$ & $30 / 1$ & $13 / 1$ & $8 / 4$ \\
\hline \multicolumn{5}{|l|}{ Clinical presentation $n(\%)$} \\
\hline Endocrine symptoms & $47(82)$ & $26(84)$ & $10(71)$ & $11(92)$ \\
\hline Cushing's syndrome & $31(54)$ & $24(78)$ & $3(21)$ & $4(34)$ \\
\hline Cushing's syndrome and virilization & $6(10)$ & $0(0)$ & $2(14)$ & $4(34)$ \\
\hline Virilization & $9(16)$ & $1(3)$ & $5(36)$ & $3(24)$ \\
\hline Endocrine hypertension & $1(2)$ & $1(3)$ & $0(0)$ & $0(0)$ \\
\hline Incidentaloma & $10(18)$ & $5(16)$ & $4(29)$ & $1(8)$ \\
\hline \multicolumn{5}{|l|}{ Functional status $n(\%)$} \\
\hline Glucocorticoid only & $33(58)$ & $27(87)$ & $3(21)$ & $3(25)$ \\
\hline Sex steroids only & $5(9)$ & $0(0)^{\prime}$ & $5(37)$ & $0(0)$ \\
\hline Mixed & $13(23)$ & $1(3)$ & $3(21)$ & $9(75)$ \\
\hline Nonfunctional & $6(10)$ & $3(10)$ & $3(21)$ & $0(0)$ \\
\hline Curative surgery $n(\%)$ & $49(86)$ & $31(100)$ & $14(100)$ & $4(33)$ \\
\hline
\end{tabular}

an abnormal hormonal profile. Forty-nine patients $(86 \%)$ underwent curative surgery.

\section{Macroscopic findings and Weiss score}

Macroscopic findings and Weiss scores are summarized in Table 2. Forty-five patients (79\%) had localized tumors: 31 patients $(54 \%)$ had tumors of $\leq 5 \mathrm{~cm}$ in size (McFarlane stage I), and 14 patients $(25 \%)$ had tumors of $>5 \mathrm{~cm}$ in size (McFarlane stage II). Twelve patients $(21 \%)$ had disseminated tumors at diagnosis (McFarlane stages III and IV): four patients had tumors invading adjacent organs (kidney: one, veins: three), and eight patients had distant metastases; all of these tumors were $>5 \mathrm{~cm}$ in size.

All patients with obviously malignant tumors (stages III and IV) had a Weiss score of 4 or more, and 42 patients $(93 \%)$ with localized tumors (stage I and II) had a Weiss score of 3 or less.

\section{Genetic abnormalities}

Most patients $(98 \% ; n=56)$ were informative for at least one $11 \mathrm{p} 15$ marker, and $81 \%(n=46)$ were informative for at least one of the three $17 \mathrm{p} 13$ markers. The prevalence of $17 \mathrm{p} 13 \mathrm{LOH}$ and $11 \mathrm{p} 15 \mathrm{UPD}$ and overexpression of the IGF-II gene are shown in Table 2. The presence of $17 \mathrm{p} 13 \mathrm{LOH}$ and 11p15 UPD and overexpression of the IGF-II gene were not associated with adrenal hyperfunction. Genetic abnormalities were frequent in stage III-IV tumors, which were obviously malignant, and were less common in localized tumors (stages I and II).

\section{Analysis of cyclin E levels}

Figure 1 shows cyclin E LI as a function of McFarlane stage (Fig. 1A), Weiss score (Fig. 1B) and presence of genetic abnormalities (Fig. 1C).

Table 2 Macroscopic, microscopic, genetic and immunohistochemical features in 57 patients with sporadic adrenocortical tumors.

\begin{tabular}{|c|c|c|c|c|c|}
\hline & $\begin{array}{l}\text { All patients } \\
\quad(n=57)\end{array}$ & $\begin{array}{c}\text { McFarlane stage I } \\
\text { (localized }) \\
(n=31)\end{array}$ & $\begin{array}{c}\text { McFarlance stage II } \\
\text { (localized) } \\
(n=14)\end{array}$ & $\begin{array}{c}\text { McFarlane stage III-IV } \\
\text { (disseminated) } \\
(n=12)\end{array}$ & $\begin{array}{c}\boldsymbol{P} \\
\text { (disseminated } \\
\text { vs } \\
\text { localized) }\end{array}$ \\
\hline \multicolumn{6}{|l|}{ Tumor size } \\
\hline$(\mathrm{cm}$, mean \pm S.D. $)$ & $7.4 \pm 5.5$ & $3.5 \pm 0.7$ & $9.8 \pm 4.7$ & $14.7 \pm 4.1$ & $<0.0001^{\mathrm{a}}$ \\
\hline \multicolumn{6}{|l|}{ Weiss score } \\
\hline (mean \pm S.D.) & $2.2 \pm 2.7$ & $0.4 \pm 0.6$ & $2.4 \pm 1.8$ & $6.5 \pm 1.3$ & $<0.0001^{\mathrm{a}}$ \\
\hline \multicolumn{6}{|l|}{ Genetic abnormalities } \\
\hline 17p13 LOH $n(\%)$ & $17 / 46(37)$ & 2/25 (8) & $7 / 11(64)$ & $8 / 10(80)$ & $<0.001^{\mathrm{b}}$ \\
\hline $11 \mathrm{p} 15$ UPD $n(\%)$ & $18 / 56(32)$ & $1 / 30(3)$ & $7 / 14(50)$ & $10 / 12(83)$ & $<0.001^{\mathrm{b}}$ \\
\hline IGF-II overexpression $n(\%)$ & 21/56 (37) & $1 / 30(3)$ & 9/14 (64) & 11/12 (92) & $<0.001^{\mathrm{b}}$ \\
\hline \multicolumn{6}{|l|}{ Cyclin E LI } \\
\hline Median (range) & $1(0-80)$ & $0(0-10)$ & $5(0-70)$ & $17.5(0-80)$ & $<0.001^{a}$ \\
\hline
\end{tabular}

aNonparametric Wilcoxon test.

'Fisher's exact test or chi-square test.

LOH: loss of heterozygosity; UPD: uniparental disomy; LI: labeling index. 

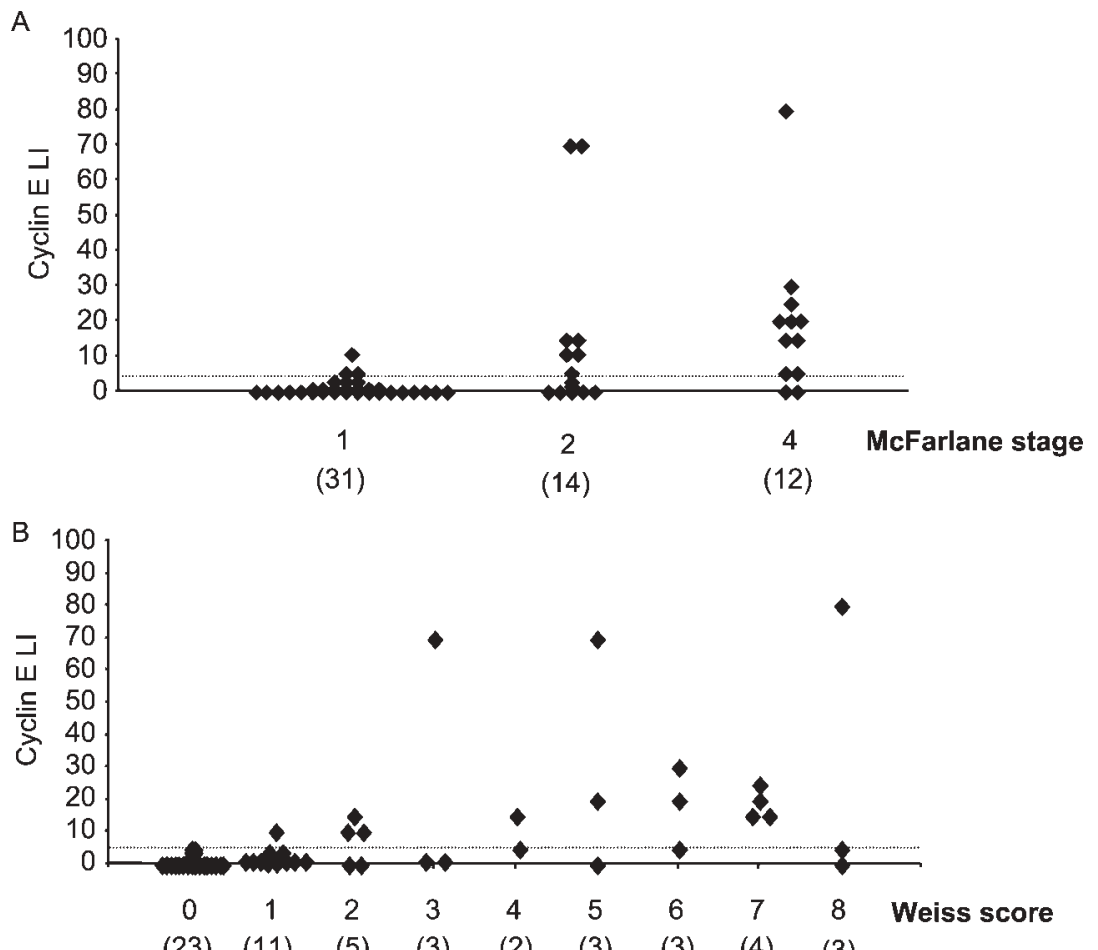

$\begin{array}{lllllllll}(23) & (11) & (5) & (3) & \text { (2) } & \text { (3) } & \text { (3) } & \text { (4) } & \text { (3) }\end{array}$

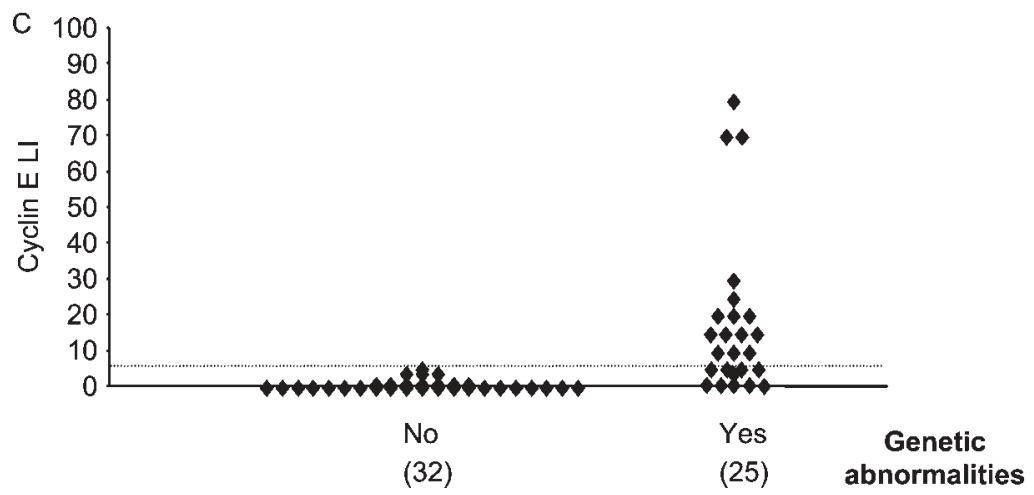

Figure 1 Cyclin E levels (\% labeled cells; LI: labeling index) as a function of McFarlane staging (A), Weiss score (B) and the presence or absence of genetic abnormalities (17p13 LOH, 11 p15 UPD and overexpression of the IGF-ll gene) (C). The cutoff value of $5 \%$ is indicated by a dotted line.

In the 31 patients with stage I tumors, cyclin E LI was $0-10 \%$ (median: $0 \%$ ) (Fig. 1A). Three patients $(10 \%)$ had cyclin E LI of $\geq 5 \%$, with associated genetic abnormalities in two of these patients, one of whom had a Weiss score of 2 . In the 14 patients with stage II tumors, cyclin E LI was $0-70 \%$ (median: 5\%). Seven patients $(50 \%)$ had cyclin E LI of $\geq 5 \%$. In the 12 patients with stage III-IV tumors, cyclin E LI was 0-80\% (median: $17.5 \%$ ). Ten patients $(83 \%)$ had cyclin E LI of $\geq 5 \%$.

In the 42 patients that had tumors with a Weiss score of 3 or less (Fig. 1B and Fig. 2A), cyclin E LI was $0-70 \%$ (median: $0 \%$ (Fig. 1B and Fig. 2B). Seven patients $(17 \%)$ had cyclin E LI of $\geq 5 \%$, and six of these seven patients had associated genetic abnormalities. In the 15 patients with tumors with a Weiss score of 4 or more (Fig. 1B and Fig. 2C), cyclin E LI was $0-80 \%$ (median: 15\%) (Fig. 1B; Fig. 2D and E). Thirteen patients $(87 \%)$ had cyclin E LI of $\geq 5 \%$. Cyclin E overproduction was not associated with a specific Weiss score criterion.

We systematically investigated three genetic abnormalities in all tumors: $17 \mathrm{p} 13 \mathrm{LOH}, 11 \mathrm{p} 15$ UPD, and IGF-II mRNA overproduction. Tumors were assigned to one of two groups: no genetic abnormality (none of these markers present) and with genetic abnormalities (at least one of these markers present). In the 32 tumors with no genetic abnormality (Fig. 1C), cyclin E LI was $0-5 \%$ (median: $0 \%$ ). In the 25 tumors with at least one genetic abnormality, cyclin 

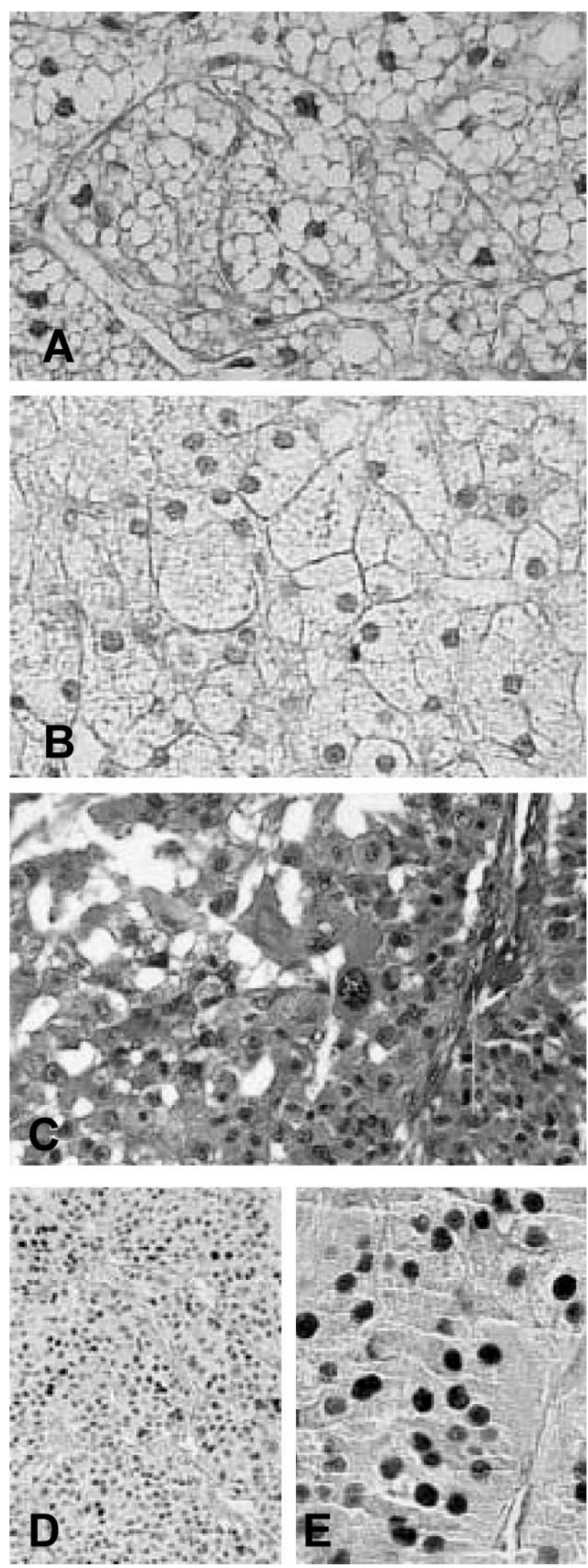

E LI was $0-80 \%$ (median: $10 \%$ ), and 19 patients (76\%) had cyclin E LI of $\geq 5 \%$. Cyclin E overproduction was not associated with a specific genetic abnormality.

\section{Disease-free survival analysis}

We carried out a prognostic study for the 49 patients that underwent curative surgery. In this group, the median duration of follow-up was 44.1 months (range: 6.7 months-8.7 years). The Kaplan-Meier estimate of disease-free survival was $86 \%$ (95\% CI: $74.7-96.4$ ) at 5 years. During the follow-up period, two patients died of unrelated causes: ovarian cancer (one case) and amyloidosis (one case). Seven patients (14\%) displayed recurrence 6.7 months to 7.9 years after initial surgery (median: 29 months).

In univariate analysis, large tumor size, high histologic grade, $17 \mathrm{p} 13 \mathrm{LOH}, 11 \mathrm{p} 15$ UPD and overexpression of the IGF-II gene were found to be strong predictors of shorter disease-free survival (Table 3 and Fig. 3A-D). Thirty-six patients showed fewer than two genetic abnormalities and 18 patients showed at least two genetic abnormalities. The presence of two or more genetic abnormalities was highly predictive of shorter disease-free survival, with a relative risk of 40 (95\% CI: 5.1-313.6). The disease-free survival curve shown in Fig. 3E indicated that cyclin E overproduction was also highly predictive of shorter disease-free survival, with a relative risk of 7.6 (95\% CI: 1.5-39.1; $P=0.016$; Table 3). Indeed, the Kaplan-Meier estimate of disease-free survival was $97 \%$ at 5 years $(95 \%$ CI: $90.6-100)$ in the group of patients with a cyclin E LI of $<5 \%$ and $59 \%$ at 5 years $(95 \%$ CI: $31.6-86.9)$ in the group of patients with a cyclin E LI of $\geq 5 \%$.

We then investigated whether the combination of cyclin E labeling with other known prognostic factors, such as Weiss score or $17 \mathrm{p} 13 \mathrm{LOH}$, would improve the prognostic evaluation. Cyclin $\mathrm{E}$ was not found to have an independent prognostic value when compared with Weiss score $(\mathrm{RR}=3.6,95 \% \quad \mathrm{CI}$ : 0.5-25.4; $P=0.20)$ or $17 \mathrm{p} 13 \mathrm{LOH}(\mathrm{RR}=0.7,95 \% \mathrm{CI}: 0.1-$ 5.9; $P=0.73)$, but the multivariate analysis was impaired by the size of the series and the low frequency of events (recurrence in seven cases).

\section{Discussion}

Benign and malignant adrenocortical tumors are usually distinguished by clinical, hormonal and

\footnotetext{
Figure 2 Hematoxylin-eosin (HE) and immunohistochemical (IHC) staining for cyclin $E$ of two different adrenocortical tumors. ( $A$ and B) Adrenocortical tumor with a Weiss score of 0 (A: HE $\times 400$; B: IHC staining of cyclin $E \times 400$ ). (C-E) Adrenocortical tumor with a Weiss score of 8 (C: HE $\times 400$; D: IHC staining of cyclin $E$ $\times 25$; E: IHC staining of cyclin $\mathrm{E} \times 400$ ).
} 
Table 3 Univariate analysis comparing disease-free survival for various prognostic factors (log rank tests).

\begin{tabular}{|c|c|c|c|}
\hline Variable & Relative risk & $\begin{array}{c}95 \% \text { confidence } \\
\text { interval }\end{array}$ & $P$ value \\
\hline Tumor size $(\mathrm{cm})(\leq 5$ vs $>5)$ & * & * & 0.0001 \\
\hline Histologic grade (Weiss score) ( $\leq 3$ vs $\geq 4$ ) & 18 & $3.5-94.1$ & 0.0006 \\
\hline 17p13 LOH (normal vs LOH) & 14.9 & $1.7-127.3$ & 0.014 \\
\hline $11 \mathrm{p} 15.5$ UPD (normal vs UPD) & 11.8 & $2.3-60.8$ & 0.003 \\
\hline IGF-II gene expression (normal vs high) & 13.8 & $1.7-114.8$ & 0.015 \\
\hline Cyclin E LI ( $<5$ vs $\geq 5 \%)$ & 7.6 & $1.5-39.1$ & 0.016 \\
\hline
\end{tabular}

LOH: loss of heterozygosity; UPD: uniparental disomy; LI: labeling index.

* It was not possible to calculate relative risk because there were no recurrences in the group of patients with tumor size of $\leq 5 \mathrm{~cm}$.

pathologic features $(3,37)$. However, in localized tumors (McFarlane stages I and II), it is sometimes difficult to distinguish between tumors with an adverse prognosis and those that are truly benign. Indeed, pathologic examination with determination of Weiss score is useful but subject to limitations. We therefore need to identify other prognostic factors for use on a routine basis. Tumorigenesis is tightly linked to abnormal regulation of the cell cycle, and there is growing recognition of the role of cyclins, CDK and CKI $(17,38)$. CKI downregulate the kinase activity of cyclin-CDK complexes, thereby negatively regulating cell-cycle progression (38). In a recent study, Stojadinovic et al. investigated in adrenocortical tumors important components of the p53 pathway by use of an immunohistochemical multimolecular profiling approach with Ki-67, p53, mdm-2, cyclin D1, Bcl-2, p21 and p27 antibodies (39). They demonstrated the molecular complexity and heterogeneity of adrenocortical carcinoma by showing 10 different phenotypes for 31 tumors, and they concluded that tumor staging and morphologic evaluation were essential in determining prognosis for patients with adrenocortical tumors. In a previous study, we have shown by a molecular approach that, in malignant adrenocortical tumors, 11 p15 UPD is responsible for the loss of CDKN1C gene expression and is associated with increased expression of cyclin E, CDK2 and CDK4 and with high activity of G1 cyclin-CDK complexes (15). In a recent study based on transcriptome analysis, Giordano et al. (14) looked for genes specifically associated with malignant adrenocortical tumors. They clearly demonstrated frequent overexpression of IGFII in malignant tumors, confirming previous data from several groups $(6,7,9)$. More interesting, they also identified several other genes, including that encoding cyclin E, as being specifically associated with malignant adrenocortical tumors.

In this study, we used immunohistochemistry to investigate cyclin $\mathrm{E}$ levels and to assess their prognostic value in a series of 57 sporadic adrenocortical tumors. This series is interesting for two major reasons: it is a large series reporting well-documented clinical, hormonal, genetic and pathologic characteristics of adrenocortical tumors in patients followed at a single center, and to our knowledge it is the first study investigating cyclin E levels in adrenocortical tumors by this method.

Cyclin E overproduction was associated with clearly clinically malignant tumors, and was correlated with larger tumor size, high Weiss score and the presence of genetic abnormalities. These immunochemical data confirm our previous Western immunoblot results that demonstrated an increase in cyclin $\mathrm{E}$ protein levels in malignant adrenocortical tumors (15). Our results are also consistent with those for other tumors, showing that cyclin E overproduction is associated with malignancy $(23,28,40)$.

Cyclin E levels have been shown to be correlated with an adverse prognosis for breast $(18,19,25,27,33$, $35)$, stomach (20), lung $(24,30)$, liver (21), lymphoid tissue $(41)$, ovarian $(31,40,42)$ and urinary tract (22) cancers. This led us to evaluate the prognostic value of cyclin $\mathrm{E}$ in our series of tumors. The diseasefree survival analysis demonstrated that cyclin E overproduction predicted shorter survival in adrenocortical tumors. This study provides the first demonstration that cyclin E levels have a predictive value for adrenocortical tumor recurrence. However, although this study is the largest available study for a relatively rare disease, the frequency of events (recurrences in seven cases) was low, and it was not possible to assess the prognostic value of cyclin $\mathrm{E}$ in multivariate analysis (43). Nevertheless, it may be possible to establish the independent prognostic value of cyclin $\mathrm{E}$ by extending this study to a larger series of patients with more outcome events.

Immunohistochemistry has been shown to be a useful method for assessing the prognostic value of cyclin E, particularly in breast ductal carcinoma (25), epithelial ovarian carcinoma $(31,42)$, non-small-cell lung carcinoma (30), colorectal carcinoma (44) and carcinoma of the ampulla of Vater (45). Our results indicate that this simple method is also useful in the prognostic assessment of adrenocortical tumors.

In conclusion, this study establishes that cyclin E overproduction is of adverse prognostic significance in adrenocortical tumors. We now need to extend this study to a larger series of patients with more outcome 
A Weiss score

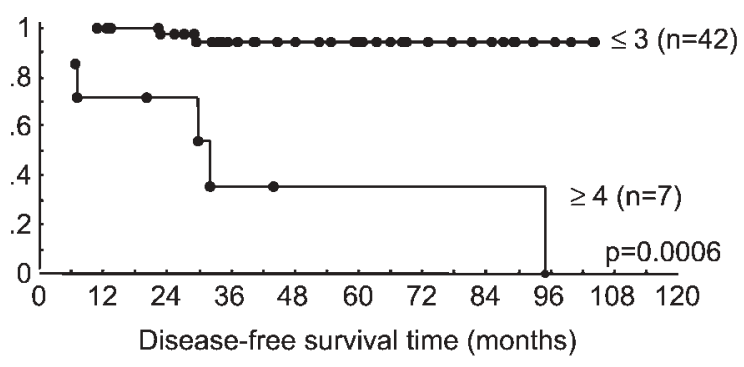

B

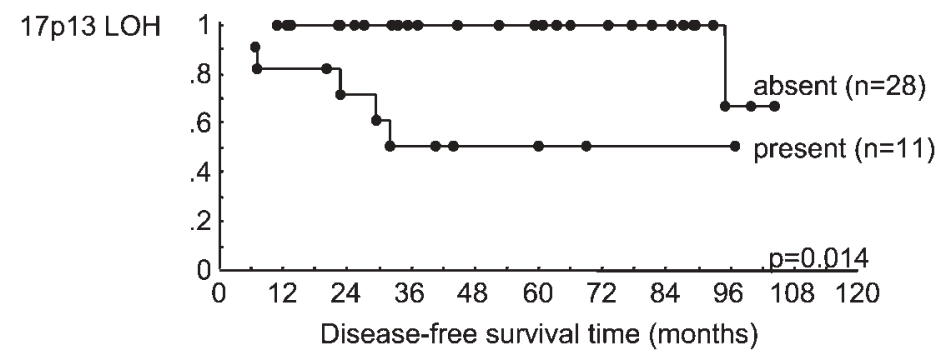

C

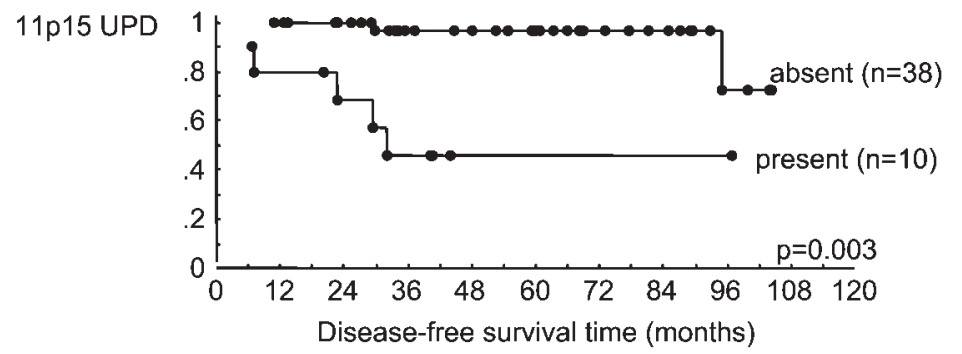

D

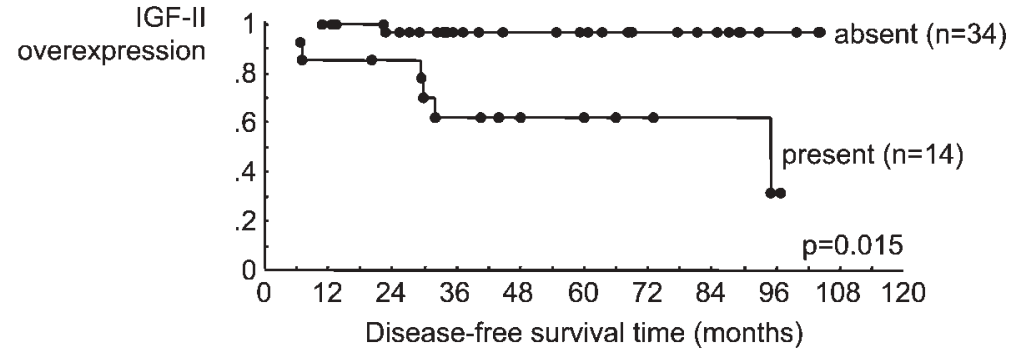

Cyclin E
Labeling Index

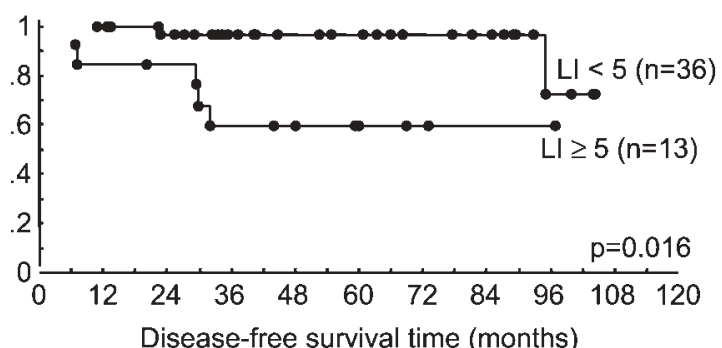

Figure 3 Kaplan-Meier disease-free survival curves according to Weiss score (A) or comparing patients with tumors showing 17p13 $\mathrm{LOH}$ and normal heterozygous profiles (B), 11 p15 uniparental disomy (UPD) and normal heterozygous profiles (C), high and normal IGF-II gene mRNA contents (D), and low or high cyclin E labeling index (E).

events to determine whether the evaluation of cyclin $\mathrm{E}$ levels could provide useful prognostic information beyond that provided by known genetic and pathologic prognostic factors.

\section{Acknowledgements}

This work was supported by the Assistance PubliqueHôpitaux de Paris and PHRC grant AOM 95201 for 
the Comete Network. F.T. was the recipient of a grant from Assistance Publique-Hôpitaux de Paris.

\section{References}

1 Luton J, Cerdas S, Billaud L, Thomas G, Guilhaume B, Bertagna X et al. Clinical features of adrenocortical carcinoma, prognostic factors and the effect of mitotane therapy. New England Journal of Medicine 1990322 1195-1201.

2 McFarlane D. Cancer of the adrenal cortex: the natural history, prognosis and treatment in a study of fifty-five cases. Annals of the Royal College of Surgeons of England 195823 155-186.

3 Weiss L. Comparative histologic study of 43 metastasizing and nonmetastasizing adrenocortical tumors. American Journal of Surgical Pathology 19848 163-169.

4 Gicquel C, Bertagna X, Gaston V, Coste J, Louvel A, Baudin E, Bertherat J, Chapuis Y, Duclos JM, Schlumberger M, Plouin PF, Luton JP \& Le Bouc Y. Molecular markers and long-term recurrences in a large cohort of patients with sporadic adrenocortical tumors. Cancer Research $2001616762-6767$.

5 Yano T, Linehan M, Anglard P, Lerman M, Daniel L, Stein C, Robertson CN, LaRocca R \& Zbar B. Genetic changes in human adrenocortical carcinomas. Journal of the National Cancer Institute $198981518-523$.

6 Ilvesmäki V, Kahri A, Miettinen P \& Voutilainen R. Insulin-like growth factors (IGFs) and their receptors in adrenal tumors: high IGF-II expression in functional adrenocortical carcinomas. Journal of Clinical Endocrinology and Metabolism $1993 \mathbf{7 7}$ 852-858.

7 Gicquel C, Bertagna X, Schneid H, Leblond-Francillard M, Luton J, Girard F \& Le Bouc Y. Rearrangements at 11p15 locus and overexpression of insulin-like growth factor-II gene in sporadic adrenocortical tumors. Journal of Clinical Endocrinology and Metabolism 199478 1444-1453.

8 Gicquel C, Bertagna X \& Le Bouc Y. Recent advances in the pathogenesis of adrenocortical tumours. European Journal of Endocrinology $1995133133-144$.

9 Gicquel C, Raffin-Sanson M, Gaston V, Bertagna X, Plouin P, Schlumberger M, Louvel A, Luton JP \& Le Bouc Y. Structural and functional abnormalities at $11 \mathrm{p} 15$ are associated with the malignant phenotype in sporadic adrenocortical tumors. Study on a series of 82 tumors. Journal of Clinical Endocrinology and Metabolism 199782 2559-2565.

10 Kjellman M, Roshani L, Teh B, Kallioniemi O, Höög A, Gray S, Farnebo LO, Holst M, Backdahl M \& Larsson C. Genotyping of adrenocortical tumors: very frequent deletions of the MEN1 locus in 11q13 and of a 1-centimorgan region in 2p16. Journal of Clinical Endocrinology and Metabolism $1999 \mathbf{8 4} 730-735$.

11 Heppner C, Reincke M, Agarwal S, Mora P, Allolio B, Burns A, Spiegel AM \& Marx SJ. MEN1 gene analysis in sporadic adrenocortical tumors. Journal of Clinical Endocrinology and Metabolism $199984216-219$.

12 Gortz B, Roth J, Speel E, Krahenmann A, De Krijger R, Matias-Guiu X, Muletta-Feurer S, Rutmann K, Saremaslani P, Heitz PU \& Komminoth P. MEN1 gene mutation analysis of sporadic adrenocortical lesions. International Journal of Cancer $199980373-379$.

13 Schulte K, Mengel M, Heinze M, Simon D, Scheuring S, Köhrer K \& Roher HD. Complete sequencing and messenger ribonucleic acid expression analysis of the MEN I gene in adrenal cancer. Journal of Clinical Endocrinology and Metabolism 200085 441-448.

14 Giordano TJ, Thomas DG, Kuick R, Lizyness M, Misek DE, Smith AL, Sanders D, Aljundi RT, Gauger PG, Thompson NW, Taylor JM \& Hanash SM. Distinct transcriptional profiles of adrenocortical tumors uncovered by DNA microarray analysis. American Journal of Pathology $2003 \mathbf{1 6 2} 521-531$.

15 Bourcigaux N, Gaston V, Logie A, Bertagna X, Le Bouc Y \& Gicquel C. High expression of cyclin E and G1 CDK and loss of function of p57KIP2 are involved in proliferation of malignant sporadic adrenocortical tumors. Journal of Clinical Endocrinology and Metabolism $200085322-330$.

16 Donnellan R \& Chetty R. Cyclin D1 and human neoplasia. Molecular Pathology 199851 1-7.

17 Donnellan R \& Chetty R. Cyclin E in human cancers. FASEB Journal $199913773-780$.

18 Nielsen NH, Arnerlov C, Emdin SO \& Landberg G. Cyclin E overexpression, a negative prognostic factor in breast cancer with strong correlation to oestrogen receptor status. British Journal of Cancer $1996 \mathbf{7 4} 874-880$.

19 Porter PL, Malone KE, Heagerty PJ, Alexander GM, Gatti LA, Firpo EJ, Daling JR \& Roberts JM. Expression of cell-cycle regulators p27Kip1 and cyclin E, alone and in combination, correlate with survival in young breast cancer patients. Nature Medicine $19973222-225$.

20 Sakaguchi T, Watanabe A, Sawada H, Yamada Y, Yamashita J, Matsuda M, Nakajima M, Miwa T, Hirao T \& Nakano H. Prognostic value of cyclin $\mathrm{E}$ and p53 expression in gastric carcinoma. Cancer $1998 \mathbf{8 2} 1238-1243$.

21 Peng SY, Chou SP \& Hsu HC. Association of downregulation of cyclin D1 and of overexpression of cyclin E with p53 mutation, high tumor grade and poor prognosis in hepatocellular carcinoma. Journal of Hepatology 199829 281-289.

22 Furihata M, Ohtsuki Y, Sonobe H, Shuin T, Yamamoto A, Terao N \& Kuwahara M. Prognostic significance of cyclin E and p53 protein overexpression in carcinoma of the renal pelvis and ureter. British Journal of Cancer 199877 783-788.

23 Noguchi T, Dobashi Y, Minehara H, Itoman M \& Kameya T. Involvement of cyclins in cell proliferation and their clinical implications in soft tissue smooth muscle tumors. American Journal of Pathology $20001562135-2147$.

24 Fukuse T, Hirata T, Naiki H, Hitomi S \& Wada H. Prognostic significance of cyclin $\mathrm{E}$ overexpression in resected non-small cell lung cancer. Cancer Research 200060 242-244.

25 Donnellan R, Kleinschmidt I \& Chetty R. Cyclin E immunoexpression in breast ductal carcinoma: pathologic correlations and prognostic implications. Human Pathology 200132 89-94.

26 Ohbu M, Kobayashi N \& Okayasu I. Expression of cell cycle regulatory proteins in the multistep process of oesophageal carcinogenesis: stepwise over-expression of cyclin $\mathrm{E}$ and $\mathrm{p} 53$, reduction of p21(WAF1/CIP1) and dysregulation of cyclin D1 and p27(KIP1). Histopathology $200139589-596$.

27 Keyomarsi K, Tucker SL, Buchholz TA, Callister M, Ding Y, Hortobagyi GN, Bedrosian I, Knickerbocker C, Toyofuku W, Lowe M, Herliczek TW \& Bacus SS. Cyclin E and survival in patients with breast cancer. New England Journal of Medicine 2002347 1566-1575.

28 Kato N, Watanabe J, Jobo T, Nishimura Y, Fujisawa T, Kamata Y \& Kuramoto H. Immunohistochemical expression of cyclin $\mathrm{E}$ in endometrial adenocarcinoma (endometrioid type) and its clinicopathological significance. Journal of Cancer Research and Clinical Oncology $2003129222-226$.

29 Kuhling H, Alm P, Olsson H, Ferno M, Baldetorp B, Parwaresch R \& Rudolph P. Expression of cyclins E, A, and B, and prognosis in lymph node-negative breast cancer. Journal of Pathology 2003 $199424-431$.

30 Dobashi Y, Jiang SX, Shoji M, Morinaga S \& Kameya T. Diversity in expression and prognostic significance of G1/S cyclins in human primary lung carcinomas. Journal of Pathology 2003 $199208-220$.

31 Farley J, Smith LM, Darcy KM, Sobel E, O'Connor D, Henderson B, Morrison LE, Birrer MJ \& Gynecologic Oncology Group. Cyclin E expression is a significant predictor of survival in advanced, suboptimally debulked ovarian epithelial cancers: a Gynecologic Oncology Group study. Cancer Research 200363 1235-1241.

32 Tzankov A, Zimpfer A, Lugli A, Krugmann J, Went P, Schraml P et al. High-through-put tissue microarray analysis of G1-cyclin alterations in classical Hodgkin's lymphoma indicates overexpression of cyclin E1. Journal of Pathology 2003199 201-207. 
33 Han S, Park K, Bae BN, Kim KH, Kim HJ, Kim YD et al. Prognostic implication of cyclin E expression and its relationship with cyclin D1 and p27Kip1 expression on tissue microarrays of node negative breast cancer. Journal of Surgical Oncology $200383241-247$.

34 Zhou Q, He Q \& Liang LJ. Expression of p27, cyclin E and cyclin A in hepatocellular carcinoma and its clinical significance. World Journal of Gastroenterology 20039 2450-2454.

35 Lindahl T, Landberg G, Ahlgren J, Nordgren H, Norberg T, Klaar S et al. Overexpression of cyclin E protein is associated with specific mutation types in the p53 gene and poor survival in human breast cancer. Carcinogenesis 200425 375-380.

36 Yasui W, Kuniyasu H, Yokozaki H, Semba S, Shimamoto F \& Tahara E. Expression of cyclin E in colorectal adenomas and adenocarcinomas: correlation with expression of Ki-67 antigen and p53 protein. Virchows Archives 1996429 13-19.

37 Hough AJ, Hollifield JW, Page DL \& Hartmann WH. Prognostic factors in adrenal cortical tumors. A mathematical analysis of clinical and morphologic data. American Journal of Clinical Pathology 197972 390-399.

38 Sherr CJ. Cancer cell cycles. Science 1996 274 1672-1677.

39 Stojadinovic A, Ghossein RA, Hoos A, Nissan A, Marshall D, Dudas $\mathrm{M}$ et al. Adrenocortical carcinoma: clinical, morphologic, and molecular characterization. Journal of Clinical Oncology 200220 941-950.

40 Sui L, Dong Y, Ohno M, Sugimoto K, Tai Y, Hando T et al. Implication of malignancy and prognosis of p27(kip1), cyclin E, and
Cdk2 expression in epithelial ovarian tumors. Gynecologic Oncology 200183 56-63.

41 Erlanson M, Portin C, Linderholm B, Lindh J, Roos G \& Landberg G. Expression of cyclin E and the cyclin-dependent kinase inhibitor p27 in malignant lymphomas - prognostic implications. Blood $199892770-777$

42 Rosenberg E Demopoulos RI, Zeleniuch Jacquette A, Yee H, Sorich J et al. Expression of cell cycle regulators p57(KIP2), cyclin D1, and cyclin E in epithelial ovarian tumors and survival. Human Pathology 200132 808-813.

43 Katz MH. Multivariable analysis: a primer for readers of medical research. Annals of Internal Medicine 2003138 644-650.

44 Li JQ, Miki H, Ohmori M, Wu F \& Funamoto Y. Expression of cyclin E and cyclin-dependent kinase 2 correlates with metastasis and prognosis in colorectal carcinoma. Human Pathology 200132 945-953.

45 Li X, Hui AM, Shi YZ, Sun L, Takayama T \& Makuuchi M. Deregulation of G1/S transition is a common event in carcinoma of the ampulla of Vater. Hepatogastroenterology $2002 \mathbf{4 9} 1239-1244$.

Received 22 December 2003

Accepted 24 February 2004 